\title{
Survey of management practices related to bovine respiratory disease in preweaned calves on California dairies
}

\author{
W. J. Love, ${ }^{* 1}$ T. W. Lehenbauer, ${ }^{*} \dagger$ B. M. Karle,ł Lindsey E. Hulbert,§ Randall J. Anderson,\# \\ A. L. Van Eenennaam,II T. B. Farver, $\dagger$ and S. S. Aly* $\dagger^{2}$ \\ *Veterinary Medicine Teaching and Research Center, School of Veterinary Medicine, University of California, Davis, Tulare 93274 \\ †Department of Population Health and Reproduction, School of Veterinary Medicine, University of California, Davis 95616 \\ ¥Cooperative Extension, Division of Agriculture and Natural Resources, University of California, Orland, 95963 \\ §Department of Animal Sciences and Industry, Kansas State University, Manhattan 66506 \\ \#Animal Health and Food Safety Services, California Department of Food and Agriculture, Modesto 95358 \\ IIDepartment of Animal Science, University of California, Davis 95616
}

\section{ABSTRACT}

In the spring of 2013, a survey of California (CA) dairies was performed to characterize management practices related to bovine respiratory disease in preweaned calves, compare these practices across geographic regions of the state, and determine the principal components that explain the variability in management between herds. The questionnaire consisted of 53 questions divided into 6 sections to assess management practices affecting dairy calves from precalving to weaning. The questionnaire was mailed to 1,523 grade A licensed dairies in CA and 224 responses (14.7\%) were collected. Survey response rates were similar over the 3 defined regions of CA: northern $\mathrm{CA}$, northern San Joaquin Valley, and the greater southern CA region. The mean size of respondent herds was 1,423 milking cows. Most dairies reported raising preweaned calves on-site (59.7\%). In $93.3 \%$ of dairies, preweaned calves were raised in some form of individual housing. Nonsaleable milk was the most frequent liquid diet fed to preweaned heifers $(75.2 \%)$. Several important differences were identified between calf-raising practices in $\mathrm{CA}$ and practices reported in recent nationwide studies, including herd sizes, housing practices, and sources of milk fed to heifers. The differences between the CA and nationwide studies may be explained by differences in herd size. Regional differences within CA were also identified. Compared with the 2 other regions, northern CA dairies were found to have smaller herds, less Holstein cattle, calves remained with dams for longer

\footnotetext{
Received January 29, 2015.

Accepted October 25, 2015.

${ }^{1}$ This manuscript is part of the dissertation by W. J. Love to the University of California at Davis, Graduate Group in Epidemiology, in partial fulfillment of the requirements for the Doctor of Philosophy degree.

${ }^{2}$ Corresponding author: saly@ucdavis.edu
}

periods of time after calving, were more likely to be certified organic dairies, and raised their own calves more often. Principal component analysis was performed and identified 11 components composed of 28 variables (questions) that explained $66.5 \%$ of the variability in the data. The identified components and questions will contribute to developing a risk assessment tool for bovine respiratory disease in preweaned dairy calves.

Key words: dairy calves, preweaning, California dairies, bovine respiratory disease

\section{INTRODUCTION}

Bovine respiratory disease (BRD) is an important economic disease in the North American dairy industry (Sischo et al., 1990). It is the second most common cause of death in preweaned dairy heifers and the most common cause of death in weaned dairy cattle (USDA, 2010). Bacterial agents that cause BRD, such as Mannheimia haemolytica, Pasteurella multocida, and Histophilus somnus, may be isolated from the upper respiratory tracts of healthy cattle (Ames et al., 2002; Callan and Garry, 2002). Viruses such as bovine respiratory syncytial virus and bovine herpesvirus type 1 are also considered etiologic agents of BRD (Gershwin, 2007; Jones and Chowdhury, 2010; Windeyer et al., 2015). In addition, BRD has a multifactorial etiology and commonly occurs following events that compromise the immune system of the respiratory tract, such as failure of transfer of passive immunity (Virtala et al., 1999), viral infections (Martin and Bohac, 1986; Czuprynski et al., 2004), poor air quality (Lago et al., 2006), over-crowding, and stress (Snowder, 2009).

Prevention and control of BRD requires an understanding of the factors and management practices associated with respiratory disease (Patrick, 2009). Several studies have described the relationship between management practices and BRD (Perez et al., 1990; Lago 
et al., 2006; Pithua et al., 2009; Windeyer et al., 2014), but such studies have not been translated into practical guidelines for producers who raise calves (Stanton, 2009). Recommended changes in calf management to control BRD must not only effectively reduce economic losses, but should also be practical and compatible with contemporary dairy management practices (Patrick, 2009).

Previous dairy studies performed by the USDA National Animal Health Monitoring System (NAHMS) have collected information about dairy calf-management practices on US dairies (USDA, 2002, 2010) and have generalized findings regarding dairy heifer practices over broad eastern and western regions, but management of dairies can meaningfully differ between and within states in the same geographic region. The categories in which herd size was reported in the NAHMS studies may not suit the larger herd sizes in California. In 2013, the average herd size in California was 1,186 cows/herd, which is much larger than the national average of 196 cows/herd (CDFA, 2013). In the 2007 NAHMS study, herd size was reported categorically, with the largest category containing herds of 500 cows or more, yet only $20 \%$ of the herds sampled had 500 cows or more (USDA, 2010).

California's unique milk-pricing system has created challenges for California dairy producers in recent years (Ellerby, 2010), and California's climate allows for housing systems that are not practical in many other parts of the country (Davis, 1954; Lago et al., 2006). Hence, a clear description of current preweaned dairy calf management on California dairies is required to identify achievable and effective recommendations for BRD control within the state. Similar studies have been used previously to assess other diseases or management practices in California (Aly et al., 2014) and elsewhere (Dutil et al., 1999). Therefore, the objectives of the current survey were to characterize management practices related to BRD in preweaned calves on California dairies, compare these practices across geographic regions of the state, and to determine the principal components that explain the variability in management between herds. Results of the survey will be used to develop an on-farm BRD risk assessment tool that can be used to identify BRD risk factors.

\section{MATERIALS AND METHODS}

\section{Questionnaire Design}

A survey instrument was designed to collect information about management practices thought to be associated with the incidence of BRD in preweaned calves on
California dairies. The questionnaire was tested using in-person interviews with producers and veterinarians. The questionnaire's final 53 questions were partitioned into 6 sections: herd demographics, calving and newborn calf management, colostrum management, preweaned calf management, weaning practices, and disease monitoring and prevention. An additional optional section was included to allow respondents to provide contact information if they were interested in participating in the continuation study and to provide feedback about the questionnaire. The study was reviewed by the University of California, Davis Institutional Review Board and granted exemption status.

\section{Survey and Data Collection}

A list of all 1,523 licensed grade A dairies in California in 2013 served as a sampling frame. Each dairy was randomly assigned a confidential number, which was used as the only unique identifier for each dairy during analysis. Dairies on the list were mailed a survey packet containing a copy of the questionnaire, a postage-paid addressed business reply envelope, and an information cover letter. Respondents were given the option of returning the completed questionnaire using the enclosed postage-paid envelope or completing the survey online. Responses were also solicited from volunteers at the 2013 World Ag Expo (WAE) in Tulare, California, and in person from dairy producers familiar to the authors. To improve questionnaire response rate, dairies received a reminder card 2 wk after the initial questionnaire package. In addition, a second questionnaire followed by a reminder card were sent a month later to dairies that did not respond. Finally, respondents that completed and returned the questionnaire were entered in a drawing to win an iPad 2 (Apple, Cupertino, CA).

\section{Questionnaire Sections}

Herd Demographics. The first section of the questionnaire assessed baseline descriptive information about the responding dairy. Questions related to the respondent's role on the dairy, the number of milking cows in the herd, the breeds of milking cows in the herd, the county where the dairy was located, if the dairy was a certified organic dairy, and if the dairy had a working relationship with a veterinarian or veterinary practice.

Calving and Newborn Calf Management. The questions in this section included use of group and individual maternity pens, the degree of shelter provided by the maternity pens, how frequently the bedding in the maternity pens was changed, and how long calves 
were left with their dams after birth. The questions regarding maternity pen shelter and bedding changes were stratified by season.

Colostrum Practices. Questions in this section included the source of colostrum fed to calves, if colostrum from first-lactation cows was fed to calves, if colostrum was tested for quality, if colostrum was pasteurized, and the volume of colostrum replacer provided in the first $12 \mathrm{~h}$ of life. Colostrum source was stratified by calf sex.

Preweaned Calf Practices. Questions in this section focused on preweaned calf housing, nutrition, feeding, and medical treatment, if applicable. The source of milk fed to calves was stratified by calf sex. The questions regarding hutch and pen flooring, bedding used, and the frequency of bedding changes in calf housing were stratified by season.

Weaning Practices. Questions in this section inquired about weaning age, age at which calves were moved into groups, and group sizes.

Health and Vaccination Practices. The final section included questions regarding if a scoring system or facility- or dairy-specific protocol was used to diagnose BRD, clinical signs used to detect BRD, dairy staff responsible for identifying and treating BRD in calves, BRD treatment protocol, and routine testing for bovine viral diarrhea virus. Additional questions inquired about the age at which intranasal, modified-live, or killed virus vaccines were administered to calves or cows, if applicable.

\section{Statistical Analysis}

Descriptive Statistics. Proportions and their standard errors were calculated for categorical and ordinal variables. Confidence intervals for proportions were calculated using the normal distribution approximation method (Daniel, 2005c). Median categories were additionally reported where appropriate, whereas mean and standard error were reported for continuous variables. Descriptive statistics were performed using Stata 13.1 (StataCorp, College Station, TX).

Comparison of Management Practices Across Regions. Dairy responses were compared across regions to determine if management practices were relatively homogeneous across the state or varied by region (Figure 1). California was initially divided into 4 regions: northern California (NCA), northern San Joaquin Valley (NSJV), southern San Joaquin Valley, and southern California. Due to a low response rate from southern California dairies, the southern San Joaquin Valley and southern California were combined into a single region, labeled greater southern California (GSCA).
Global tests for differences over all regions were performed first, and post hoc pair-wise comparisons were performed only if global tests were significant at $P<0.05$. One-way ANOVA was initially used to test for global differences in herd size across regions. Levene's test was used to assess the assumption that herd size variabilities were equal across regions and, if violated, Welch's test was used to test for global differences in herd size instead of ANOVA. Pair-wise differences in regional mean herd sizes were compared using Tukey's honestly significant difference (Daniel, 2005c). The Kruskal-Wallis (K-W) mean rank test (Daniel, 2005a) was used to test for global differences across regions in the following ordinal variables: percent of Holstein cattle in the herd, median age at first calving, and time newborn calves spent with their dams. Pair-wise comparisons of ordinal variables were performed by comparing ranks with Bonferroni-Dunn adjusted error rates (Daniel, 1990). Overall differences in proportions were tested using Chi-squared tests for independence or Fisher's exact test (Daniel, 2005b) for the following nominal variables: certified organic milk

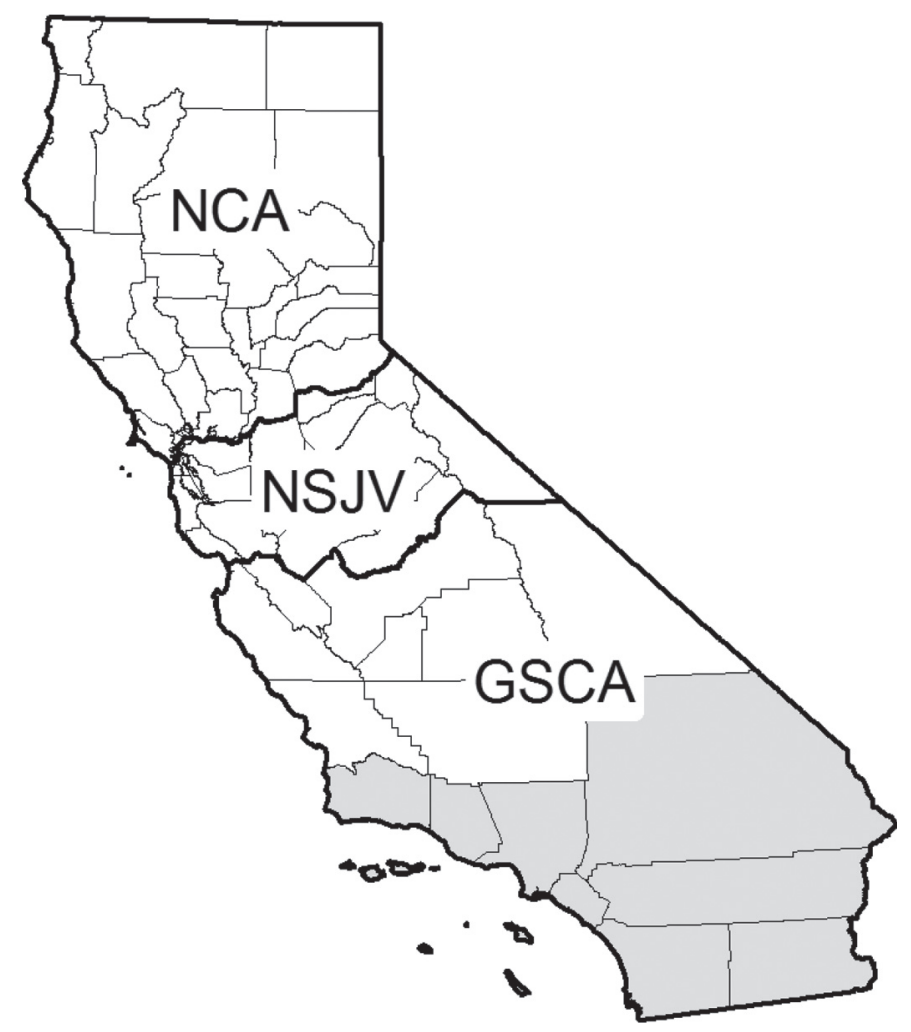

Figure 1. Map of counties in northern California (NCA), northern San Joaquin Valley (NSJV), and greater southern California (GSCA) regions for comparison of calf raising practices. Southern San Joaquin Valley counties (unshaded region of GSCA) and southern California counties (shaded region of GSCA) were combined due to a low response rate from southern California. 
producers, premises that use group maternity pens, and premises that raised their own preweaned calves. Post hoc pair-wise comparisons of proportions of regional proportions were tested using the Chi-squared tests for independence with critical points adjusted using the Bonferroni-Dunn correction for multiple comparisons. Regional comparisons were performed using SPSS release 22 (IBM, Armonk, NY).

Principal Component Analysis. Principal component analysis (PCA) was performed to summarize the correlation structure of dairy-management practices and identify important principal components. The PCA was restricted to only responses from premises that raised preweaned calves on-site, and only respondents that provided valid responses to all the variables were included in the PCA. The PCA was performed on a matrix of Spearman's rank correlations based on a subset of 28 continuous, ordinal, and dichotomous variables. Questionnaire items with multiple, nominal response levels were also included in the subset if the response levels could be arranged in a biologically justified order. Questionnaire items not biologically relevant to the incidence of BRD, such as county and the role of the individual completing the questionnaire were excluded. Similarly, questions with responses stratified by season were excluded to avoid over-estimating correlations. Only responses for heifers were included from questionnaire items that were stratified by sex due to the increased value of heifers as replacement animals compared with bulls at the time the questionnaire was conducted. A total of 28 variables met the criteria for inclusion in the PCA, which was performed using SPSS release 22 (IBM). Principal components with eigenvalues greater than 1 were retained for interpretation (Kaiser, 1960) based on variables with loading weights of 0.4 or higher. Varimax rotation was performed to allow factors to better align to the underlying biological components while keeping the components mutually independent (Stevens, 2009).

\section{RESULTS}

\section{Descriptive Statistics}

Questionnaires were mailed to 1,523 California licensed grade A milk producers. One hundred ninetyeight questionnaires were returned by mail, 9 responses were completed online, 6 responses were recruited in person by one of the researchers, and 21 responses were recruited from dairy producers at WAE. Six of the 9 online responses could be identified as dairies on the mailing list of licensed grade A producers. Six mailed responses, 3 responses from the WAE, and 1 online response were found to be unusable due to large numbers of incomplete questionnaire items or multiple questionnaires from the same dairy. The remaining 224 responses (95.7\% of all responses) were used in the analyses. The overall usable response rate was $14.7 \%$. The NCA and NSJV regions had response rates of $13.5 \%$ (38 responses) and 14.5\% (97 responses), respectively. The GSCA region, which had a response rate of $11.6 \%$, was created by combining the southern San Joaquin Valley (79 responses, $14.0 \%$ response rate) and southern California (9 responses, $8.0 \%$ response rate) regions due to paucity of data from the latter region. The county of one response could not be determined.

Table 1 summarizes respondents' roles, herd size and breed composition, organic status, and rearing location of calves. The average reported herd size was 1,417 milking cows and herds ranged in size from 85 to 9,200 cows. Approximately 1 out of 10 dairies were certified organic dairies and nearly all dairies reported having a regular working relationship with a veterinarian or veterinary practice. Table 2 summarizes age at first calving and maternity pen management: median age category of heifers at first calving was 22 to $25 \mathrm{mo}$, and open lots with shade and inside a barn were the most frequent maternity pen housing system reported during the summer and winter, respectively. Responding dairies indicated bedding was used less frequently in maternity pens in the summer than in the winter.

Table 3 summarizes colostrum management: most notably more than half of responding dairies reported using first-lactation colostrum, but few reported pasteurizing colostrum. Most dairies reported calves were fed $2.84 \mathrm{~L}$ (3 quarts) of colostrum replacer or more in the first $12 \mathrm{~h}$ of life $(53.1 \pm 3.4 \%, \mathrm{n}=213)$. Approximately $60 \%$ of dairies reported they raised preweaned calves on-site and fed milk twice a day. Grain was first offered to calves in the first week of life on $59.4 \%$ of dairies $( \pm 4.3 \%, \mathrm{n}=133), 33.1 \%( \pm 4.1 \%)$ during the second week of life, and later on the remainder of dairies $(7.5 \pm 2.3 \%)$. Table 4 summarizes the additional questions on preweaned calf-feeding practices.

Nearly all dairies responded that some or all preweaned calves raised on site were housed individually $(93.3 \pm 2.2 \%, \mathrm{n}=134)$, and $19.4 \%( \pm 3.4 \%)$ raised at least some calves in groups. Nearly all dairies housing calves individually used some form of a hutch to individually house calves $(92.8 \pm 2.3 \%, \mathrm{n}=125$; Table 5$)$. More than one-half of dairies that raised calves individually reported such calves could make physical contact with other calves $(51.6 \pm 4.5 \%, \mathrm{n}=126)$. Wood was the most common material used in hutches and pens $(52.7 \pm 4.4 \%, \mathrm{n}=129)$, with plastic and metal less frequently reported as the primary calf housing material 
Table 1. Summary of herd information from 224 responses to a calf-raising practices questionnaire distributed to grade A licensed California dairies

\begin{tabular}{|c|c|c|c|c|c|}
\hline \multirow[b]{2}{*}{ Question } & \multirow[b]{2}{*}{$\mathrm{n}$} & \multirow[b]{2}{*}{ Estimate } & \multirow[b]{2}{*}{$\mathrm{SE}$} & \multicolumn{2}{|c|}{$95 \% \mathrm{CI}$} \\
\hline & & & & Lower & Upper \\
\hline Respondent role (\%) & 223 & & & & \\
\hline Herd owners & & 78.0 & 2.8 & 72.6 & 83.5 \\
\hline Herd managers & & 14.3 & 2.3 & 9.7 & 19.0 \\
\hline Other & & 7.6 & 1.8 & 4.1 & 11.1 \\
\hline Herd size $(n)$ & 221 & $1,417.1$ & 96.4 & $1,232.1$ & $1,610.9$ \\
\hline Predominant breed $(\%)$ & 223 & & & & \\
\hline Holstein & & 77.4 & 2.8 & 72.7 & 82.2 \\
\hline Jersey & & 8.2 & 1.8 & 5.5 & 10.9 \\
\hline Other & & 14.4 & 2.3 & 9.9 & 18.9 \\
\hline Certified organic dairy (\%) & 224 & 9.8 & 2.0 & 5.9 & 13.7 \\
\hline Preweaned calves raised on premises (\%) & 221 & 59.7 & 3.3 & 53.3 & 66.2 \\
\hline Weaned calves raised on premises (\%) & 219 & 74.0 & 3.0 & 68.2 & 79.8 \\
\hline
\end{tabular}

$(33.3 \pm 4.2$ and $17.8 \pm 3.4 \%$, respectively). Most dairies did not use bedding in either the summer or the winter $(51.1 \pm 4.2 \%, \mathrm{n}=139)$. Among the dairies that did use bedding for preweaned calves, straw and shavings were the most frequently reported bedding materials in both the summer $(24.4 \pm 3.8 \%$ and $13.0 \pm 2.9 \%$, respectively, $\mathrm{n}=131)$ and the winter $(35.4 \pm 4.2 \%$ and 16.2 $\pm 3.2 \%$, respectively, $\mathrm{n}=130)$. Dirt was the most com-

Table 2. Summary of maternity pen management practices from 224 responses to a calf-raising practices questionnaire distributed to grade A licensed California dairies

\begin{tabular}{|c|c|c|c|c|c|}
\hline \multirow[b]{2}{*}{ Question } & \multirow[b]{2}{*}{$\mathrm{n}$} & \multirow[b]{2}{*}{ Estimate } & \multirow[b]{2}{*}{$\mathrm{SE}$} & \multicolumn{2}{|c|}{$95 \% \mathrm{CI}$} \\
\hline & & & & Lower & Upper \\
\hline Average heifer age at first calving (\%) & 223 & & & & \\
\hline$<22 \mathrm{mo}$ & & 8.1 & 1.8 & 4.5 & 11.6 \\
\hline $22-25 \mathrm{mo}$ & & 79.4 & 2.7 & 74.1 & 84.7 \\
\hline$>25 \mathrm{mo}$ & & 10.3 & 2.0 & 6.3 & 14.3 \\
\hline Varies & & 2.2 & 1.0 & 0.3 & 4.2 \\
\hline Group maternity pens (\%) & 220 & 78.2 & 2.8 & 72.7 & 83.6 \\
\hline \multicolumn{6}{|l|}{ Maternity pen style ${ }^{1}(\%)$} \\
\hline Summer & 215 & & & & \\
\hline Pasture & & 5.6 & 1.6 & 2.5 & 8.6 \\
\hline Lot without shade & & 4.7 & 1.4 & 1.8 & 7.5 \\
\hline Lot with shade & & 39.5 & 3.3 & 33.0 & 46.1 \\
\hline Barn with outside access & & 32.6 & 3.2 & 26.3 & 38.8 \\
\hline Inside a barn only & & 25.1 & 3.0 & 19.3 & 30.9 \\
\hline Winter & 217 & & & & \\
\hline Pasture & & 3.7 & 1.3 & 1.2 & 6.2 \\
\hline Lot without shade & & 3.7 & 1.3 & 1.2 & 6.2 \\
\hline Lot with shade & & 34.1 & 3.2 & 27.8 & 40.4 \\
\hline Barn with outside access & & 25.3 & 3.0 & 19.6 & 31.1 \\
\hline Inside a barn only & & 38.2 & 3.3 & 31.8 & 44.7 \\
\hline \multicolumn{6}{|c|}{ How often is bedding changed in maternity pens? $(\%)$} \\
\hline Summer & 217 & & & & \\
\hline Daily & & 10.6 & 2.1 & 6.5 & 14.7 \\
\hline More than weekly & & 18.9 & 2.7 & 13.7 & 24.1 \\
\hline Weekly or less & & 42.9 & 3.4 & 36.3 & 49.4 \\
\hline No bedding & & 27.6 & 3.0 & 21.7 & 33.6 \\
\hline Winter & 212 & & & & \\
\hline Daily & & 13.2 & 2.3 & 8.6 & 17.8 \\
\hline More than weekly & & 32.5 & 3.2 & 26.2 & 38.9 \\
\hline Weekly or less & & 41.0 & 3.4 & 34.4 & 47.7 \\
\hline No bedding & & 13.2 & 2.3 & 8.6 & 17.8 \\
\hline Time calves left with dam (\%) & 219 & & & & \\
\hline Always $<1 \mathrm{~h}$ & & 28.8 & 3.1 & 22.8 & 34.8 \\
\hline$<1 \mathrm{~h}$ during the day, more at night & & 26.9 & 3.0 & 21.1 & 32.8 \\
\hline Always $>1 \mathrm{~h}$ & & 44.3 & 3.4 & 37.7 & 50.9 \\
\hline
\end{tabular}

\footnotetext{
${ }^{1}$ Indicates question to which respondents could select a combination of responses.
} 
mon material covering the surfaces between hutch rows or pens $(45.6 \pm 4.5 \%, \mathrm{n}=125)$. Approximately one third of dairies that reported raising their own calves also reported flushing below elevated calf housing units to remove calf waste $(34.6 \pm 4.2 \%, \mathrm{n}=130)$.

Respondent dairies frequently reported raising weaned calves on site $(74.0 \pm 3.0 \%, \mathrm{n}=219)$. All but one of the dairies that raised preweaned calves also reported raising their weaned calves $(99.2 \pm 0.01 \%, \mathrm{n}=133)$, and approximately one-third of respondent dairies that did not raise preweaned calves raised weaned calves $(34.5 \pm 5.1 \%, \mathrm{n}=87)$. More than half of respondents reported weaning calves at $\geq 65 \mathrm{~d}$ of age $(53.5 \pm 4.0 \%$, $\mathrm{n}=159)$. Approximately one-fourth of dairies reported calves were grouped before weaning $(25.8 \pm 3.5 \%, \mathrm{n}$ $=155$ ), and dairies that grouped calves after weaning reported they most frequently did so after calves had been weaned for more than 1 wk $(44.3 \pm 4.6 \%$, $\mathrm{n}=$ 115). Most dairies moved calves into groups of more than 12 animals $(52.2 \pm 4.0 \%, \mathrm{n}=157)$.
Identifying and treating animals with pneumonia was reported to be the responsibility of calf feeders or calf managers on most dairies $(60.1 \pm 3.4$ and $53.7 \pm$ $3.5 \%$, respectively, $\mathrm{n}=203$ ). A scoring system or facility specific protocol was used to detect pneumonia on $20.9 \%( \pm 2.8 \%, \mathrm{n}=215)$ of dairies, and $69.4 \%( \pm 3.2 \%$, $\mathrm{n}=209)$ of dairies reported they had a specific treatment protocol for pneumonia developed with the herd veterinarian. The clinical signs most frequently used to detect pneumonia were coughing $(88.1 \pm 2.2 \%, \mathrm{n}=$ $210)$, depression $(84.1 \pm 2.5 \%)$, rapid respiration $(81.4$ $\pm 2.7 \%)$, and head tilt $(75.7 \pm 3.0 \%)$. Approximately $71.0 \%( \pm 3.9 \%, \mathrm{n}=138)$ of dairies reported feeding and caring for sick preweaned calves after healthy calves and $33.1 \%( \pm 4.0 \%, \mathrm{n}=137)$ of dairies moved sick preweaned calves to a hospital pen. The most commonly reported type of fly control products used where preweaned calves were raised were spray products $(57.0$ $\pm 4.3 \%, \mathrm{n}=135)$ and granular products $(61.5 \pm 4.2 \%$, $\mathrm{n}=135)$.

Table 3. Summary of colostrum practices from 224 responses to a calf-raising practices questionnaire distributed to grade A licensed California dairies

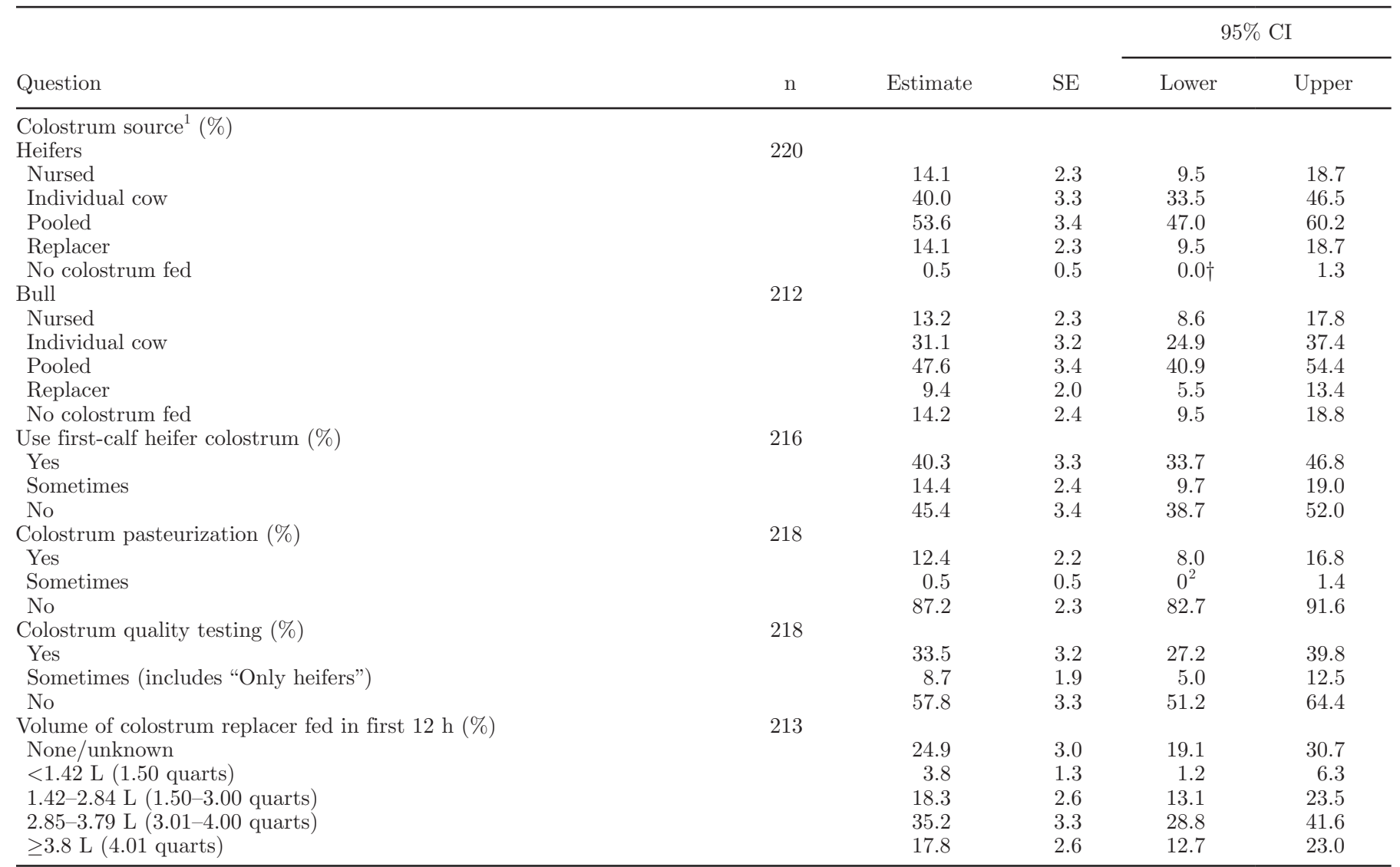

${ }^{1}$ Indicates question to which respondents could select a combination of responses.

${ }^{2}$ Bound calculated for confidence interval using normal approximation lies outside 0 to 1 range. 
Table 4. Summary of pre-weaned calf feeding practices from a subset of 134 dairies that reported raising pre-weaned calves on the premises taken from a total 224 responses to a questionnaire distributed to grade A licensed California dairies

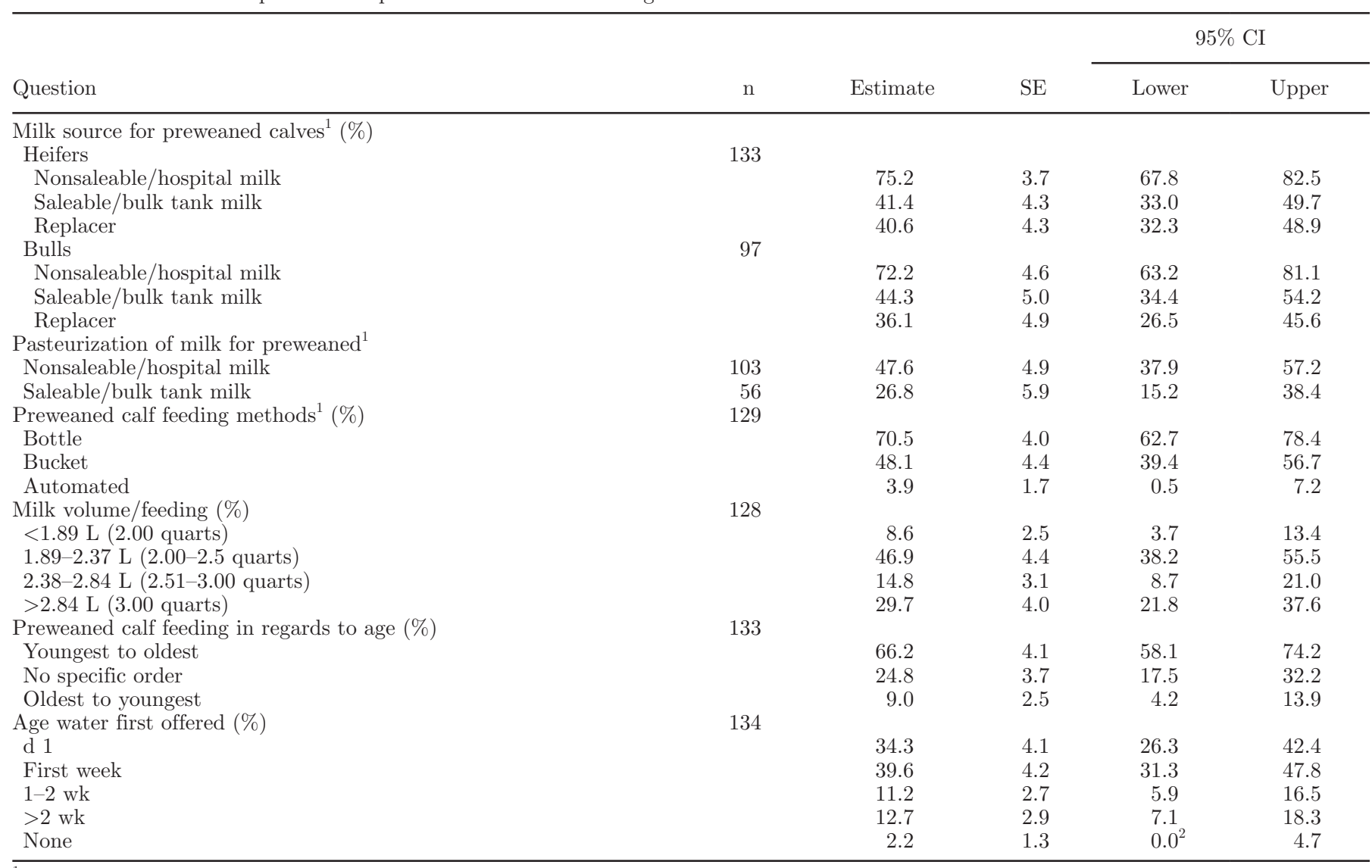

${ }^{1}$ Indicates question to which respondents could select a combination of responses.

${ }^{2}$ Bound calculated for confidence interval using normal approximation lies outside the 0 to 1 range.

Intranasal viral vaccines were administered to calves at least once in the first 2 wk of life on approximately one half $(54.9 \pm 3.5 \%, \mathrm{n}=204)$, and at weaning on $17.6 \%( \pm 2.7 \%)$ of the respondent dairies. Modified live vaccines were more frequently used than intranasal vaccines at weaning $(31.6 \pm 3.3 \%, \mathrm{n}=196)$. Killed vaccines were not commonly used at weaning $(8.6 \pm$ $2.1 \%, \mathrm{n}=186)$. Adult cows were vaccinated with an intranasal vaccine on $11.3 \%$ of dairies $( \pm 2.2 \%, \mathrm{n}=204)$, with modified live vaccines on $58.7 \%$ of dairies $( \pm 3.5 \%$, $\mathrm{n}=196)$ and with killed vaccines on $39.2 \%( \pm 3.6 \%, \mathrm{n}$ $=186$ ). Few dairies tested for persistent bovine viral diarrhea virus infection in calves $(6.2 \pm 1.7 \%, \mathrm{n}=211)$.

\section{Regional Comparisons}

Response Rate. Regional response rates for the mailed questionnaire (mailed and online responses) were $13.5 \%$ for NCA, $14.5 \%$ for NSJV, and $11.6 \%$ for GSCA. If responses recruited in person and from the WAE were included, the proportions increased to
$16.5 \%$ from NCA, $15.8 \%$ from NSJV, and $12.9 \%$ from GSCA. The response rates did not vary by region for mailed questionnaire responses $\left(\chi^{2}=2.36, P=0.31\right)$ or for all responses $\left(\chi^{2}=2.84, P=0.24\right)$, with an overall significance of $P=0.05$.

Herd Size. Variance of herd sizes across regions was found to be unequal (Levene's statistic $=8.85, P<$ 0.01 ), hence Welch's test was used to assess regional differences in herd sizes. Herd sizes across regions were found to be significantly different (Welch's $F=27.28$, $P<0.01)$. Post hoc pair-wise comparisons showed that NCA herds $(543 \pm 100$ cows, $\mathrm{n}=37)$ were significantly smaller than herds in NSJV $(1,342 \pm 134$ cows, $\mathrm{n}=95)$ and GSCA $(1,871 \pm 172$ cows, $\mathrm{n}=88)$. Northern San Joaquin Valley herds were smaller than the mean size of GSCA herds $(P<0.05$ over all significant comparisons).

Percent Holstein. The percent Holstein cattle in herds was not equal over all regions $\left(\mathrm{K}-\mathrm{W} \chi^{2}=8.79, P\right.$ $=0.01)$, with the remaining breeds either Jersey, other breeds, or crossbreds. Northern California dairy herds 
Table 5. Summary of preweaned calf housing practices from a subset of 134 dairies that reported raising preweaned calves on the premises taken from a total 224 responses to a questionnaire distributed to grade A licensed California dairies

\begin{tabular}{|c|c|c|c|c|c|}
\hline \multirow[b]{2}{*}{ Question } & \multirow[b]{2}{*}{$\mathrm{n}$} & \multirow[b]{2}{*}{ Estimate } & \multirow[b]{2}{*}{ SE } & \multicolumn{2}{|c|}{$95 \% \mathrm{CI}$} \\
\hline & & & & Lower & Upper \\
\hline Individual housing systems ${ }^{1}(\%)$ & 125 & & & & \\
\hline Hutch on ground & & 26.4 & 3.9 & 18.7 & 34.1 \\
\hline Elevated hutch & & 58.4 & 4.4 & 49.8 & 67.0 \\
\hline Hutch with exercise area & & 16.8 & 3.3 & 10.2 & 23.4 \\
\hline Fenced pen & & 6.4 & 2.2 & 2.1 & 10.7 \\
\hline Tether & & 0.8 & 0.8 & $0.0^{2}$ & 2.4 \\
\hline \multicolumn{6}{|l|}{ Hutch or pen flooring ${ }^{1}(\%)$} \\
\hline \multicolumn{6}{|l|}{ Summer } \\
\hline Slatted & & 55.5 & 4.4 & 46.9 & 64.1 \\
\hline Soil & & 33.6 & 4.2 & 25.4 & 41.8 \\
\hline Solid & & 11.7 & 2.8 & 6.1 & 17.3 \\
\hline Other & & 10.2 & 2.7 & 4.9 & 15.4 \\
\hline \multicolumn{6}{|l|}{ Winter } \\
\hline Slatted & & 52.3 & 4.4 & 43.7 & 61.0 \\
\hline Soil & & 37.5 & 4.3 & 29.1 & 45.9 \\
\hline Solid & & 11.7 & 2.8 & 6.1 & 17.3 \\
\hline Other & & 11.7 & 2.8 & 6.1 & 17.3 \\
\hline \multicolumn{6}{|l|}{ Calf housing location ${ }^{1}(\%)$} \\
\hline Summer & 127 & & & & \\
\hline Outside, no cover & & 38.6 & 4.3 & 30.1 & 47.0 \\
\hline Outside, under shade structure & & 23.6 & 3.8 & 16.2 & 31.0 \\
\hline Inside shed & & 27.6 & 4.0 & 19.8 & 35.3 \\
\hline Inside barn & & 18.1 & 3.4 & 11.4 & 24.8 \\
\hline Winter & 126 & & & & \\
\hline Outside, no cover & & 42.1 & 4.4 & 33.4 & 50.7 \\
\hline Outside under shade structure & & 18.3 & 3.4 & 11.5 & 25.0 \\
\hline Inside shed & & 27.0 & 4.0 & 19.2 & 34.7 \\
\hline Inside barn & & 19.0 & 3.5 & 12.2 & 25.9 \\
\hline
\end{tabular}

${ }^{1}$ Indicates question to which respondents could select a combination of responses.

${ }^{2}$ Bound calculated for confidence interval using normal approximation lies outside the 0 to 1 range.

were composed of $62.5 \%( \pm 6.8 \%, \mathrm{n}=39)$ Holstein cattle on average, NSJV dairy herds were composed of $79.6 \%( \pm 3.6 \%, \mathrm{n}=96)$ Holstein cattle, on average, and GSCA herds were composed of $81.5 \%( \pm 3.5 \%$, $\mathrm{n}=86$ ). Northern California herds had significantly fewer Holstein cattle than GSCA herds by proportion but did not have a significantly different proportion of Holstein cattle than NSJV herds. The proportion of Holstein cattle in NSJV herds was not significantly different than in GSCA herds $(P<0.05$ for all significant comparisons).

Certified Organic Producers. The proportion of dairies that were certified as organic producers was not homogeneous across regions (Fisher's exact $P<0.01$ ). Pair-wise comparisons showed NCA dairies were significantly more likely to be certified organic $(47.4 \pm 8.1 \%$, $\mathrm{n}=38)$ than were dairies in the NSJV $(3.1 \pm 1.8 \%, \mathrm{n}=$ $96)$ and GSCA regions $(2.3 \% \pm 1.6 \%, \mathrm{n}=86)$. Northern San Joaquin Valley dairies were not significantly more likely to be certified organic than GSCA dairies $(P<0.01$ for all significant comparisons $)$.
Age at First Calving. The median age of heifers at first calving was not significantly different among regions $\left(\mathrm{K}-\mathrm{W} \chi^{2}=3.98, P=0.14\right)$.

Group Maternity Pens. The proportion of dairies that used group maternity pens did not differ significantly among regions $\left(\chi^{2}=0.80, P=0.71\right)$.

Time Newborn Calves Were Left with Dams. The amount of time calves were left with their dams after birth was not equal across regions $\left(\mathrm{K}-\mathrm{W} \chi^{2}=\right.$ 19.02, $P<0.005)$. The median time newborn calves were left with their dams was more than $1 \mathrm{~h}$ on NCA dairies and less than $1 \mathrm{~h}$ during the day, but more than $1 \mathrm{~h}$ if the calf was born during the night on NSJV and GSCA dairies. Respondents from NCA herds left calves with dams significantly longer after birth than NSJV and GSCA herds $(P<0.05$ over all significant comparisons). No significant difference was noted in the median time newborn calves were left with their dams between dairies in NSJV and GSCA regions.

Preweaned Calves Raised On Site. The proportion of dairies that raised their own preweaned calves 
Table 6. Summary of subjective interpretations of 11 factors extracted from 28 calf husbandry practice variables collected from 93 responses to a questionnaire distributed to grade A licensed California dairies

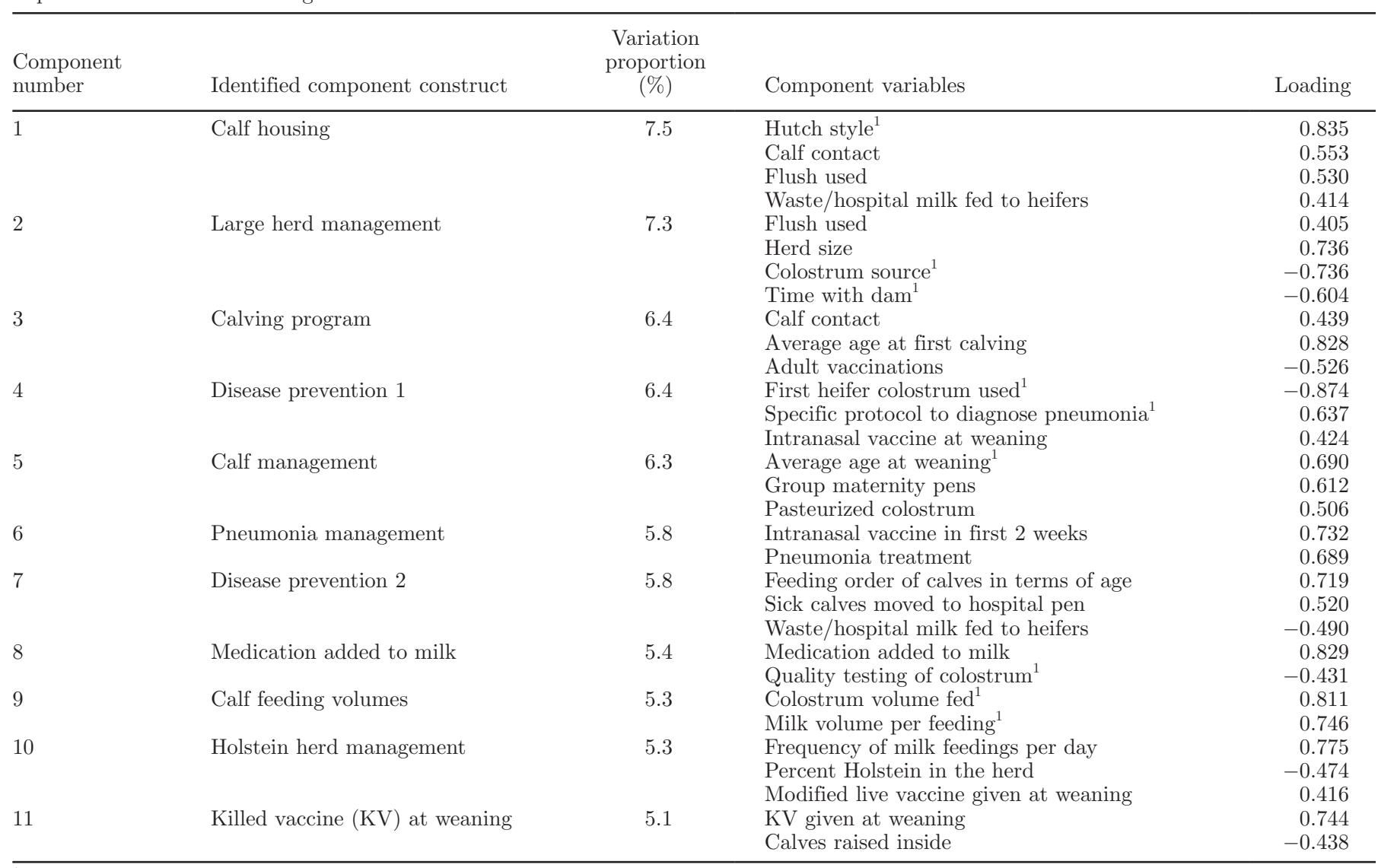

${ }^{1}$ Indicates an ordinal variable.

on site was not homogeneous across regions (Fisher's exact $P<0.005)$. Pair-wise comparisons showed that a significantly larger proportion of NCA dairies raised their own calves $(100 \%, \mathrm{n}=39)$ than NSJV (44.2 \pm $5.1 \%, \mathrm{n}=95)$ and GSCA $(50.0 \pm 5.5 \%, \mathrm{n}=84)$ dairies $(P<0.01$ for all significant comparisons). The proportion of dairies that raised their own calves was not significantly different between NSJV and GSCA.

$\boldsymbol{P C A}$. Ninety-three of the 134 respondent dairies that raised calves provided complete responses to all 28 variables included in the PCA. Eleven components with eigenvalues greater than 1 were identified and retained for interpretation by the Kaiser rule. The 11 retained components accounted for $66.5 \%$ of total variance of the data. The varimax-rotated components had eigenvalues ranging between 1.43 and 2.09 and accounted for $66.5 \%$ of the variance in the data. All varimax-rotated components had at least 1 variable that loaded 0.65 or higher, and 17 of the 28 variables $(60.7 \%)$ had a loading of 0.6 or greater on at least 1 component. Constructs could be identified for all 11 of the varimax rotated components (Table 6).

\section{DISCUSSION}

Results of our survey describe the current calf-raising practices on California dairies. California dairies account for almost $20 \%$ of the dairy cattle in the United States (CDFA, 2013). The PCA identified 11 components that accounted for $66.5 \%$ of the variation in the data (Table $6)$. The 11 components identified the important questions considered for a risk-assessment tool for BRD on California dairies in future research, an approach that has been adopted previously for a Johne's disease risk assessment (Berghaus et al., 2005). Previous studies have described dairy practices in western US regions aggregated across multiple states (USDA, 2002, 2010), but not recently and not specific to California. Other studies have focused on California's dairy industry, but not practices associated with BRD in preweaned calves specifically (Tavornpanich et al., 2008; Moore et al., 2010; Meyer et al., 2011; Mayo et al., 2012; Aly et al., 2014), and none of the previous surveys were designed and analyzed to identify questions for a risk assessment tool like the current survey. California has the most 
dairy cattle of any other state and has the third largest average herd size after Arizona and New Mexico (CDFA, 2013). The size of the individual dairies in California and the state's contribution to the nation's dairy industry warrants research specific to California dairies to enhance calf management and reduce risk of BRD in calves. Larger herds require more efficient methods of calf care, and increased number of workers per dairy allows more specialization of labor.

A previous survey (Aly et al., 2014) reported that Holsteins were the most prevalent cattle breed on $64.5 \%$ of California's dairies, which is similar to the current survey's findings $(77.4 \%)$ but different than a recent NAHMS study (92.2\%; USDA, 2010). California dairies of all sizes were more likely to raise calves off site $(40.3 \%)$ than were dairies across the United States $(4.6 \%)$.

The importance of colostrum quality and volume fed to control BRD has been established in previous studies (Van Donkersgoed et al., 1993; Virtala et al., 1999; Gorden and Plummer, 2010). The current survey found that management on California dairies were less likely to allow calves to nurse colostrum from the dam (14.1\%) compared with dairies across the nation (36.3\%), and more likely to test colostrum quality with a colostrometer or refractometer $(33.5 \%)$ than dairies elsewhere $(5.7 \%)$. California dairies were also more likely to pool colostrum fed to heifer calves $(53.6 \%)$ compared with the remaining US dairies (21.0\%). Similarities between previous California studies and differences from nationwide studies support that nationwide findings may not be applicable to California dairies.

More California dairies fed saleable (41.4\%) and nonsaleable $(75.2 \%)$ milk to heifer calves compared with dairies in the United States (29.4\% salable and 33.4\% nonsaleable) and fewer dairies fed milk replacer (40.6\%) to heifer calves $(66.6 \%)$. The effect of milk source, volume, and frequency of feeding before weaning on BRD incidence is unclear, with some studies showing significant effects (Morrison et al., 2012; Araujo et al., 2014) and others showing none (Kehoe et al., 2007; Bach et al., 2013). Most of the surveyed dairies also reported weaning calves at older ages $(>65 \mathrm{~d})$ than elsewhere in the United States (median $56 \mathrm{~d}$ ). The direct effect of weaning age on BRD incidence has not been studied directly (Guterbock, 2014), but later weaning ages have been shown to lead to greater ADG and BW at weaning in organically raised calves (Bjorklund et al., 2013).

A greater proportion (93.3\%) of California dairies kept some or all heifers housed individually before weaning than dairies across the United States (74.9\%), and the majority of respondent dairies that raised their own calves housed them individually in wooden hutch- es. Additional information about the dimensions and structures of the hutches was not collected. However, given our experience, the majority of wooden hutches were likely the traditional "California hutch" design, which are commonly manufactured in units each made up of 3 individual calf hutches with a partial roof and no base. The latter allows for placement of the hutch on dirt or a slatted platform. The calves are typically housed in the hutches until shortly after weaning. The hutches are large enough to allow preweaned calves to turn around and lay down comfortably, and calves in adjacent hutches can make nose-to-nose contact if hutches are spaced close enough together. The slatted floor allows calf waste to pass through the bottom of the hutch for sanitation. The hutches allow workers to accurately and easily monitor the milk consumption of individual calves and easily treat the calves when illness is noted. Housing calves in hutches has been demonstrated to improve calf health by limiting the spread of pathogens (Quigley et al., 1994).

Calf-management practices on NCA dairies appear to be substantially different than practices on dairies in other regions of the state. Dairies in the NCA region were significantly smaller in herd size and proportion of Holstein cattle than dairies in the remaining 2 regions. However, NCA dairies had a greater proportion of certified organic dairies, greater proportion of dairies raising preweaned calves on site, and longer duration of time newborn calves were left with dams before being removed compared with the remaining 2 regions. The climate of the NCA region, especially the northern coastal counties, is milder than that of other regions in the state and more amenable to raising cattle on pasture. Pasture availability is also an important factor for certified organic dairy farming because $30 \%$ of the roughage for certified organic cattle must come from grazing. In contrast, NSJV and GSCA dairies had no significant differences except in terms of mean herd size, suggesting these regions may be homogeneous with respect to calf-management practices.

Three questions were identified for improvement during the course of the study. First, confusion may have been caused by the question assessing the volume of colostrum replacer fed, as another question assessing the volume of colostrum fed was accidentally omitted from the outgoing questionnaire. Respondents may have provided answers about the volume of colostrum fed instead of the volume of colostrum replacer, hence, for the purpose of the PCA analysis, the respective variable was identified as volume of colostrum fed regardless of source. Second, information was collected about the use of standardized systems for identification of calves with BRD, but further clarification regarding 
which systems are used is needed to fully understand the answers provided by the respondents. Finally, only about one half of dairies housing calves individually reported calves could make physical contact with other calves, which is lower than expected, as most individually housed calves were reported to be kept in hutches. One possible explanation for the lower calf-to-calf contact is use of individual plastic hutches, which if placed far enough apart or constructed with high solid walls may prevent such contact. Alternatively, nose-to-nose may not have been considered as physical contact to some of the questionnaire respondents, and clarification of what contact with other calves entails may be needed in future revisions.

An important limitation of the current study was its reliance upon the voluntary response of target population. It is difficult to conclude if the dairies that responded to the survey are representative of all California dairies. The mean dairy herd size in our study was 1,417 cows/herd, which was greater than a 2013 estimate of average herd size of 1,186 cows/herd (CDFA, 2013); this may indicate over representation of large herds in the current study. Response rates across regions were similar, ranging from 13.0 to $16.5 \%$; as a result, it is reasonable to conclude that all 3 regions were proportionately represented and the potential for any bias due to regional difference was small. Responses were recruited from several sources, but fewer than $12 \%$ of responses came from sources other than mailed surveys, making it unlikely that these responses had undue influence on the descriptive statistics or other comparisons. The aggregation of the southern California and southern San Joaquin Valley regions may have obscured some differences in management practices between those 2 regions.

\section{CONCLUSIONS}

The current study provided a cross-sectional description of current dairy demographics and management practices in California that may influence the incidence of BRD in preweaned dairy calves. The size, scale, and management practices of California dairies may differ compared with those for dairy herds elsewhere in the United States. Further research is needed to quantify the relationships between herd practices identified in our study and farm-specific BRD incidence to develop a risk-assessment tool.

\section{ACKNOWLEDGMENTS}

Funding for this study was provided by the University of California, Division of Agriculture and Natural Resources (Grant \#1753) and the Dairy Epidemiology
Laboratory (Aly Lab, Tulare, CA). The authors thank the survey respondents and cooperating dairy owners.

\section{REFERENCES}

Aly, S. S., H. A. Rossow, G. Acetoze, T. W. Lehenbauer, M. Payne, D. Meyer, J. Maas, and B. Hoar. 2014. Survey of beef quality assurance on California dairies. J. Dairy Sci. 97:1348-1357.

Ames, T. R., J. C. Baker, and S. E. Wiske. 2002. The bronchopneumonias (respiratory disease complex of cattle, sheep, and goats). Pages 551-570 in Large Animal Internal Medicine. 3rd ed. B. P. Smith, ed. Mosby, Philadelphia, PA.

Araujo, G., M. Terré, and A. Bach. 2014. Interaction between milk allowance and fat content of the starter feed on performance of Holstein calves. J. Dairy Sci. 97:6511-6518.

Bach, A., M. Terre, and A. Pinto. 2013. Performance and health responses of dairy calves offered different milk replacer allowances. J. Dairy Sci. 96:7790-7797.

Berghaus, R. D., J. E. Lombard, I. A. Gardner, and T. B. Farver. 2005. Factor analysis of a Johne's disease risk assessment questionnaire with evaluation of factor scores and a subset of original questions as predictors of observed clinical paratuberculosis. Prev. Vet. Med. 72:291-309.

Bjorklund, E. A., B. J. Heins, and H. Chester-Jones. 2013. Whole-milk feeding duration, calf growth, and profitability of group-fed calves in an organic production system. J. Dairy Sci. 96:7363-7370.

Callan, R. J., and F. B. Garry. 2002. Biosecurity and bovine respiratory disease. Vet. Clin. North Am. Food Anim. Pract. 18:57-77.

CDFA. 2013. California Dairy Statistics Annual 2013. Sacramento CA. Accessed Sep. 21, 2015. http://www.cdfa.ca.gov/dairy/pdf/ Annual/2013/2013_Annual_2012_Data.pdf.

Czuprynski, C. J., F. Leite, M. Sylte, C. Kuckleburg, R. Schultz, T. Inzana, E. Behling-Kelly, and L. Corbeil. 2004. Complexities of the pathogenesis of Mannheimia haemolytica and Haemophilus somnus infections: Challenges and potential opportunities for prevention? Anim. Health Res. Rev. 5:277-282.

Daniel, W. 2005a. Analysis of variance. Pages 305- 404 in Biostatistics: A Foundation for Analysis in the Health Sciences. 8th ed. John Wiley \& Sons, Hoboken, NJ.

Daniel, W. 2005b. The chi-squared distribution and the analysis of frequencies. Pages 593-678 in Biostatistics: A Foundation for Analysis in the Health Sciences. 8th ed. John Wiley \& Sons, Hoboken, NJ.

Daniel, W. 2005c. Estimation. Pages 162-212 in Biostatistics: A Foundation for Analysis in the Health Sciences. 8th ed. John Wiley \& Sons, Hoboken, NJ.

Daniel, W. W. 1990. Applied Nonparametric Statistics. 2nd ed. P.W.S.-Kent, Boston, MA.

Davis, L. R., K. M. Autrey, H. Herlich, and G. E. Hawkins. 1954. Outdoor individual portable pens compared with conventional housing for raising dairy calves. J. Dairy Sci. 37:562-565.

Dutil, L., G. Fecteau, E. Bouchard, D. Dutremblay, and J. Pare. 1999. A questionnaire on the health, management, and performance of cow-calf herds in Quebec. Can. Vet. J. 40:649-656.

Ellerby, J. 2010. Challenges and Opportunities for California's Dairy Economy. California Center for Cooperative Development, Davis, CA. Accessed Sept. 21, 2015. http://www.cccd.coop/files/ TotalReport-CaliforniaDairyChallengesAndOpportunities.pdf.

Gershwin, L. J. 2007. Bovine respiratory syncytial virus infection: Immunopathogenic mechanisms. Anim. Health Res. Rev. 8:207-213.

Gorden, P. J., and P. Plummer. 2010. Control, management, and prevention of bovine respiratory disease in dairy calves and cows. Vet. Clin. North Am. Food Anim. Pract. 26:243-259.

Guterbock, W. M. 2014. The impact of BRD: The current dairy experience. Anim. Health Res. Rev. 15:130-134.

Jones, C., and S. Chowdhury. 2010. Bovine herpesvirus type 1 (BHV1 ) is an important cofactor in the bovine respiratory disease complex. Vet. Clin. North Am. Food Anim. Pract. 26:303-321.

Kaiser, H. 1960. The application of electronic computers to factor analysis. Educ. Psychol. Meas. 20:141-151. 
Kehoe, S. I., C. D. Dechow, and A. J. Heinrichs. 2007. Effects of weaning age and milk feeding frequency on dairy calf growth, health and rumen parameters. Livest. Sci. 110:267-272.

Lago, A., S. M. McGuirk, T. B. Bennett, N. B. Cook, and K. V. Nordlund. 2006. Calf respiratory disease and pen microenvironments in naturally ventilated calf barns in winter. J. Dairy Sci. 89:4014-4025.

Martin, S. W., and J. G. Bohac. 1986. The association between serological titers in infectious bovine rhinotracheitis virus, bovine virus diarrhea virus, parainfluenza-3 virus, respiratory syncytial virus and treatment for respiratory disease in Ontario feedlot calves. Can. J. Vet. Res. 50:351-358.

Mayo, C. E., I. A. Gardner, B. A. Mullens, C. M. Barker, A. C. Gerry A. J. Guthrie, and N. J. MacLachlan. 2012. Anthropogenic and meteorological factors influence vector abundance and prevalence of bluetongue virus infection of dairy cattle in California. Vet. Microbiol. 155:158-164.

Meyer, D., P. L. Price, H. A. Rossow, N. Silva-del-Rio, B. M. Karle, P. H. Robinson, E. J. DePeters, and J. G. Fadel. 2011. Survey of dairy housing and manure management practices in California. J. Dairy Sci. 94:4744-4750.

Moore, D. A., D. A. Leach, D. Bickett-Weddle, K. Andersen, A. R Castillo, C. A. Collar, G. Higginbotham, N. Peterson, B. Reed, and M. L. Hartman. 2010. Evaluation of a biological risk management tool on large western United States dairies. J. Dairy Sci. 93:4096-4104.

Morrison, S. J., H. C. F. Wicks, A. F. Carson, R. J. Fallon, J. Twigge, D. J. Kilpatrick, and S. Watson. 2012. The effect of calf nutrition on the performance of dairy herd replacements. Animal 6:909-919.

Patrick, R. L. 2009. A dairy producer's view of respiratory disease. Anim. Health Res. Rev. 10:111-112.

Perez, E., J. P. T. M. Noordhuizen, L. A. van Wuijkhuise, and E. N. Stassen. 1990. Management factors related to calf morbidity and mortality rates. Livest. Prod. Sci. 25:79-93.

Pithua, P., S. J. Wells, S. M. Godden, and E. A. Raizman. 2009. Clinical trial on type of calving pen and the risk of disease in Holstein calves during the first $90 \mathrm{~d}$ of life. Prev. Vet. Med. 89:8-15.

Quigley, J. D., III, K. R. Martin, D. A. Bemis, L. N. D. Potgieter, C. R. Reinemeyer, B. W. Rohrbach, H. H. Dowlen, and K. C. Lamar. 1994. Effects of Housing and Colostrum Feeding on the Prevalence of Selected Infectious Organisms in Feces of Jersey Calves. J. Dairy Sci. 77:3124-3131.
Sischo, W. M., D. W. Hird, I. A. Gardner, W. W. Utterback, K. H. Christiansen, T. E. Carpenter, C. Danaye-Elmi, and B. R. Heron. 1990. Economics of disease occurrence and prevention on California dairy farms: A report and evaluation of data collected for the national animal health monitoring system, 1986-87. Prev. Vet. Med. 8:141-156.

Snowder, G. 2009. Genetics, environment and bovine respiratory disease. Anim. Health Res. Rev. 10:117-119

Stanton, A. 2009. Challenges and opportunities for managing respiratory disease in dairy calves. Anim. Health Res. Rev. 10:113-115.

Stevens, J. 2009. Applied Multivariate Statistics for the Social Sciences. 5th ed. Routledge, New York, NY.

Tavornpanich, S., W. O. Johnson, R. J. Anderson, and I. A. Gardner. 2008. Herd characteristics and management practices associated with seroprevalence of Mycobacterium avium subsp paratuberculosis infection in dairy herds. Am. J. Vet. Res. 69:904-911.

USDA. 2002. Part I: Reference of Dairy Health and Management in the United States, 2002. USDA:APHIS:VS, CEAH, National Animal Health Monitoring System, Fort Collins, CO. \#N377.1202. Accessed Sep. 21, 2015. https://www.aphis.usda.gov/animal_health/ nahms/dairy/downloads/dairy02/Dairy02_dr_PartI.pdf.

USDA. 2010. Dairy 2007, Heifer Calf Health and Management Practices on U.S. Dairy Operations, 2007. USDA:APHIS:VS, CEAH, National Animal Health Monitoring System, Fort Collins, CO. \#550.0110. Accessed Sep. 21, 2015. https://www.aphis.usda. gov/animal_health/nahms/dairy/downloads/dairy07/Dairy07_ ir_CalfHealth.pdf.

Van Donkersgoed, J., C. S. Ribble, L. G. Boyer, and H. G. Townsend 1993. Epidemiological study of enzootic pneumonia in dairy calves in Saskatchewan. Can. J. Vet. Res. 57:247-254.

Virtala, A. M., Y. T. Grohn, G. D. Mechor, and H. N. Erb. 1999 The effect of maternally derived immunoglobulin $\mathrm{G}$ on the risk of respiratory disease in heifers during the first 3 months of life. Prev. Vet. Med. 39:25-37.

Windeyer, M. C., K. E. Leslie, S. M. Godden, D. C. Hodgins, K. D. Lissemore, and S. J. LeBlanc. 2014. Factors associated with morbidity, mortality, and growth of dairy heifer calves up to 3 months of age. Prev. Vet. Med. 113:231-240.

Windeyer, M. C., K. E. Leslie, S. M. Godden, D. C. Hodgins, K. D. Lissemore, and S. J. LeBlanc. 2015. Association of bovine respiratory disease or vaccination with serologic response in dairy heifer calves up to three months of age. Am. J. Vet. Res. 76:239-245. 